ISSN 0258-7122

Bangladesh J. Agril. Res. 40(3): 451-463, September 2015

\title{
LARVICIDAL EFFICACY OF SOME INDIGENOUS PLANT EXTRACTS AGAINST EPILACHNA BEETLE, EPILACHNA VIGINTIOCTOPUNCTATA (FAB.) (COLEOPTERA: COCCINELLIDAE)
}

\author{
R. ARA ${ }^{1}$, M. A. A. BACHCHU ${ }^{2}$, M. O. KULSUM ${ }^{3}$ AND Z. I. SARKER ${ }^{4}$
}

\begin{abstract}
The study was carried out to assess the larvicidal efficacies of some indigenous plant seed extracts against epilachna beetle, Epilachna vigintioctopunctata in the laboratory of the Department of Entomology, HSTU, Dinajpur, Bangladesh. Petroleum ether and methanol solvent extracts of ata (Annona squamosa), neem (Azadirachta indica), dhutura (Datura metel) and castor (Ricinus communis) seeds were evaluated for their larvicidal properties against the larval stage of $E$. vigintioctopunctata. The result revealed that all the tested plant extracts had more or less insecticidal effect against the larvae and their progeny. Among the plant extracts, ata seed extract in methanol solvent performed the highest toxicity $\left(\mathrm{LD}_{50}\right.$ value $\left.0.031 \mathrm{mg} / \mathrm{insect}\right)$ in larval stage after 72 hours exposure time. The effects of the extracts on fecundity, fertility and $F_{1}$ adult emergence of the epilachna beetle at doses 4.0, 2.0 and $1.0 \mathrm{ml} / \mathrm{l}$ of water including untreated control were also evaluated. The result indicated that, among the extracts, ata seed extract at maximum dose $(4.0 \mathrm{ml} / \mathrm{l}$ water $)$ showed the highest efficacy with the inhibition of total eggs $(74.1 \%)$, viable eggs $(80.4 \%)$ and number of emergent adult progeny $(87.3 \%)$. The result also revealed that the number of eggs, number of viable eggs and $F_{1}$ progeny production decreased with the increase of doses. All the treated doses effectively reduced the epilachna beetle as compared to untreated control.
\end{abstract}

Keywords: Plant extracts, petroleum ether, methanol solvent, larval mortality, Epilachna vigintioctopunctata.

\section{Introduction}

Two species of epilachna beetle viz. Epilachna vigintioctopunctata (Fab.) and Epilachna dodecastigma (Wied.) are serious pests of vegetables in Bangladesh (Khan et al., 2000). Epilachna beetles are locally known as hadda beetles and common throughout the country and cause a considerable damage to a number of solanaceous, cucurbitaceous and leguminous crops (Anam et al., 2006; Rahaman et al., 2008; Islam, et al., 2011). Both adults and grubs feed voraciously by scrapping the chlorophyll of the leaves, causing characteristics skeletonization of the lamina. Affected leaves gradually dry and drop down (Srivastava and Butani, 1998).

\footnotetext{
${ }^{1-3}$ Department of Entomology, Hajee Mohammad Danesh Science and Technology University (HSTU), Dinajpur, ${ }^{4}$ Breeding division, Wheat Research Centre, Nashipur, Dinajpur, Bangladesh.
} 
Due to infestation of epilachna beetle about $80 \%$ of plants are damaged depending on place and season for prevailing environmental conditions (Rajagopal and Trivedi, 1989). The presence of this pest is one of the limiting factors in the vegetable production causing qualitative as well as quantitative losses. Synthetic chemical insecticides have been widely preferred to combat this pest problem because of their quick knock-down effect. But due to some illeffects of the chemical insecticides, there have been numerous problems, such as acute and chronic poisoning of applicators, farm workers, consumers, fishes, birds and other wild life animals etc. (National Research Council, 2000; Rohani et al., 2001). Substitutes are being strongly conceived whereby researchers are now paying much emphasis on the biologically active indigenous plant products as they are environmentally safe, biodegradable and cost effective. Plant extracts contain botanical insecticides or phytochemicals that could be used to repel, deter feeding, or limit reproduction and survival of various insect pest species including coccinellid beetles (Rajagopal and Trivedi, 1989; Swaminathan et al., 2010).

Using various plant extracts, attempts have been made to save such crops as potato (Rajagopal and Trivedi, 1989), brinjal (Sreedevi et al., 1993; Ghatak and Mondal, 2008), oilseed (Ahmed, 2007; Ahmed et al., 2010), cucumber (Mondal and Ghatak, 2009) and bitter gourd (Rahaman et al., 2008) against the attacks of the beetle. Ahmed (2007) reported that aqueous extract sprays of the castor oil plant Ricinus communis L. (F. Euphorbiaceae) reduced Epilachna attack on foliage. Subsequently, methanol extracts of $R$. communis were found to have larvicidal properties against the mosquitoes Aedes aegypti (Zahir et al., 2009). Anam et al., (2006) reported that neem oil significantly prolonged larval and pupal periods and some of the treated larvae never reached to the pupae. Pupal recovery and adult emergence were greatly reduced in treated larvae. The aqueous extract of Calotropis procera showed strong repellent activity against the Henosepilachna elaterii (Ahmed et al., 2006). The uses of plant products against vegetable pests are scanty in Bangladesh. Therefore, an attempt was made to find out the larvicidal efficacy of the seed extracts of neem, ata, dhutura and castor against the larvae of epilachna beetle.

\section{Materials and Method}

Collection and preparation of test plant seed powder: The study was conducted in the laboratory of the Department of Entomology, Hajee Mohammad Danesh Science and Technology University (HSTU), Dinajpur, Bangladesh during August 2012 to November 2012. Test plant materials, such as neem (Azadirachta indica A. Juss.), ata (Annona squamosa L.), dhutura (Datura metel L.) and castor ( $R$. communis L.) seeds were collected from the villages of the Dinajpur district. All seeds were collected at the ripening stage. Collected seeds 
were washed in the running tap water and then dried under shade in the laboratory as breakdown of various compounds may occur in sunlight. The dried seeds were then powdered in a hand grinding machine separately. Before grinding the seeds were well-dried in an oven at $40^{\circ} \mathrm{C}$ for six hours. A sieve of 60-mesh diameter was used to obtain the fine powder. Later each powder was stored in plastic containers under laboratory condition for experimental use.

Preparation of seed extract: Hundred grams of different seed powders were dissolved in $300 \mathrm{ml}$ of pure methanol (polar) and petroleum ether (non-polar) solvent separately and stirred for 30 minutes in a magnetic stirrer. The mixture was then allowed to stand for 72 hours and shaking several intervals. Then, the mixture was filtered through a filter paper (Whatman no. 42) and allowed to evaporate the solvents in water bath at $70^{\circ} \mathrm{C}$. Finally, the oily crude extracts were obtained. The oily extracts were preserved in tightly corked vials and stored in a refrigerator for experimental use.

Rearing and mass culture of the test insect (E. vigintioctopunctata): In order to obtain a huge number of beetles continuously for experimental use a mass culture was maintained in cages with potted plant of bitter gourd. The adults of $E$. vigintioctopunctata were collected from the infested bitter gourd plant cultivated in the field of Entomology Department, HSTU campus. They were sexed and one pair of beetle was released in each plant in the fine mesh nylon cages $(45 \mathrm{~cm} \times 35$ $\mathrm{cm} \times 60 \mathrm{~cm}$ ) under laboratory conditions at $28 \pm 2^{\circ} \mathrm{C}$ and $81 \pm 2 \% \mathrm{RH}$ for oviposition. After oviposition adult beetles were transferred in different cages and the egg masses were left undisturbed for hatching. After hatching the larvae and pupae were reared up to adult emergence. For continuous supply of the potted plants as food, bitter gourd seeds were sown in earthen pots every alternate day. When the plants were fed by larvae in cages, the fresh plant pot was placed attached to the adjacent pot, thus all the larvae moved to the fresh one. The number of instars was determined by their shed skin. This procedure was used to obtain a large number of larvae of the same instar (4th) at the same time for experiments.

\section{Experimental protocol}

Effect of plant extract on the larval mortality (direct toxicity): Direct toxicity tests on the larvae of epilachna beetle were conducted under laboratory conditions at $28 \pm 2^{\circ} \mathrm{C}$ and $81 \pm 2 \% \mathrm{RH}$ following Completely Randomized Design (CRD). Different concentrations of crude extracts were prepared by diluting with the respective solvents. The concentrations were 100, 50, 25, 12.5 and 6.25 $\mathrm{mg} / \mathrm{ml}$ of each plant in each solvent. Before applying extracts, the larvae were chilled for a period of 10 minutes in refrigerator. The immobilized larvae were individually picked up and 10 micro-liter solutions of different concentrations 
$(100,50,25,12.5$ and $6.25 \mathrm{mg} / \mathrm{ml})$ were applied to the dorsal surface of the thorax of each individual with the help of a micro syringe (Hamilton, USA). Ten larvae were treated in one replication. Three replications were used in each dose. The insects of control treatment were treated with the respective solvent only. The insects were then transferred into $9.0 \mathrm{~cm}$ diameter Petri dishes containing leaf disc of bitter gourd as food. Insect mortality was recorded at 24, 48 and 72 hours after treatment. The data were corrected by Abbott's (1987) formula. The probit analyses were done to estimate $\mathrm{LD}_{50}$ values with $95 \%$ fiducial limits. Heterogeneity was tested by a chi-square test.

Effect of plant extracts on the fecundity, egg hatchability, and adult population of $F_{1}$ progeny (residual effect)

The seeds of neem, ata, dhutura and castor were extracted in two solvents (petroleum spirit and methanol) for their residual effect on the fecundity, egg hatchability, and adult population of $F_{1}$ progeny. Each type of crude extract was diluted with distilled water containing $0.01 \%$ nonidet to prepare different concentrations of spray solution. The doses were 4.0,2.0, and $1.0 \mathrm{ml} / \mathrm{l}$ of water for each treatment. The total numbers of treatments were 25 and replication was thrice for each dose. The test extracts were compared with untreated control.

The entire experiment was conducted with the potted bitter gourd plant. Bitter gourd seeds were collected from regional BRAC seed centre, Dinajpur and planted in earthen pot. To prevent the pest infestation, plants were covered with mosquito net. Sprayings with different solutions were done at 40 days after sowing (DAS) by a hand sprayer. After spraying each plant was marked with marking card. To induce population build up one pair of 10-15 days old fresh healthy adult beetles were released in each plant and kept for oviposition. The total numbers of eggs in masses were counted and recorded after seven days with the help of magnifying glass and then the parent beetles were removed. Observations on total number of larvae, pupae and adult emergence ( $F_{1}$ progeny) were also counted and recorded up to adult emergence.

Statistical analysis: The experiments were conducted using CRD. The data obtained from the experiments were statistically analyzed by MSTAT-C computer program. The means of the treatments were tested by DMRT. The observed mortality data were corrected by Abbott's (1987) formula and then subjected to probit analysis.

\section{Results and Discussion}

Effect of plant seed extracts on larval mortality: The results of the larval mortality for the estimation of $\mathrm{LD}_{50}$ values, $95 \%$ confidence limits, regression 
equations and $\chi^{2}$ values were calculated and presented in Table 1 . The calculated $\mathrm{LD}_{50}$ values were $0.136,0.693,0.176,0.230 \mathrm{mg} /$ insect at 24 hours after treatment(HAT); 0.071, 0.434, 0.074, $0.115 \mathrm{mg} /$ insect after 48 HAT and 0.045, 0.163, 0.037, $0.055 \mathrm{mg} /$ insect after $72 \mathrm{HAT}$ in ata, neem, dhutura, castor seed extract respectively in petroleum spirit. Comparing the $\mathrm{LD}_{50}$ values, the order of toxicity was found as ata > dhutura > castor $>$ neem at 24 and 48 HAT whereas after 72 HAT the toxicity was dhutura $>$ ata $>$ castor $>$ neem (Table 1 ).

In methanol solvent extract, the $\mathrm{LD}_{50}$ values were found as $0.094,0.348,0.250$, $0.175 \mathrm{mg} /$ insect at $24 \mathrm{HAT} ; 0.039,0.114,0.144,0.088 \mathrm{mg} / \mathrm{insect}$ at 48 HAT and $0.031,0.046,0.073,0.050 \mathrm{mg} /$ insect at $72 \mathrm{HAT}$ in ata, neem, dhutura and castor seed extract, respectively. The toxicity rank of the seed extracts was found as ata $>$ castor > dhutura > neem at 24 HAT whereas it was found as ata > castor > neem $>$ dhutura at 48 and ata $>$ neem $>$ castor $>$ dhutura at 72 HAT (Table 1) depending on the $\mathrm{LD}_{50}$ values.

The probit regression lines of E. vigintioctopunctata larvae treated with ata, neem, dhutura and castor seed extract in two solvent at different exposure hours are presented in Fig. 1. The insect mortality rates showed positive correlation with doses in all cases. From the non-significant $\chi^{2}$ values it indicated that larval mortality did not show heterogeneity with the doses of extracts. Karunaratne and Arukwatta (2009) evaluated the methanol extracts of $A$. indica (Neem), A. reticulata, (Custard apple) and $A$. squamosa (Sugar apple) for their potential as antifeedants and insecticides for the control of E. vigintioctopunctata. They found that all three plants eliciting a highly significant reduction in food consumption at all concentrations. A. squamosa at the highest concentration (20.0 $\mathrm{g} / \mathrm{L}$ ) showed very strong antifeedant and contact toxic effect on the epilachna larvae whereas $A$. indica extract elicited a much more delayed toxic action. Swaminathan et al., (2010) investigated that Neem oil showed 60 per cent mortality at 5 per cent concentration. The leaf extract and seed kernel extract of $A$. indica had less antifeedant activity as compared to the oil formulations of $A$. indica. In the present study neem seed extract showed less toxic effect than other botanicals.

Effect of plant extracts on fecundity, hatchability, and adult population of $F_{1}$ progeny (residual effect): The results of the effect of plant extracts on the fecundity, fertility and $\mathrm{F}_{1}$ progeny production of E. vigintioctopunctata are presented in Table 2. Statistical analysis indicated that the individual effect of two solvents did not differ significantly. Probably this may happen that the solvents were not used as in spray material, these solvent were only used as in extract preparation. 


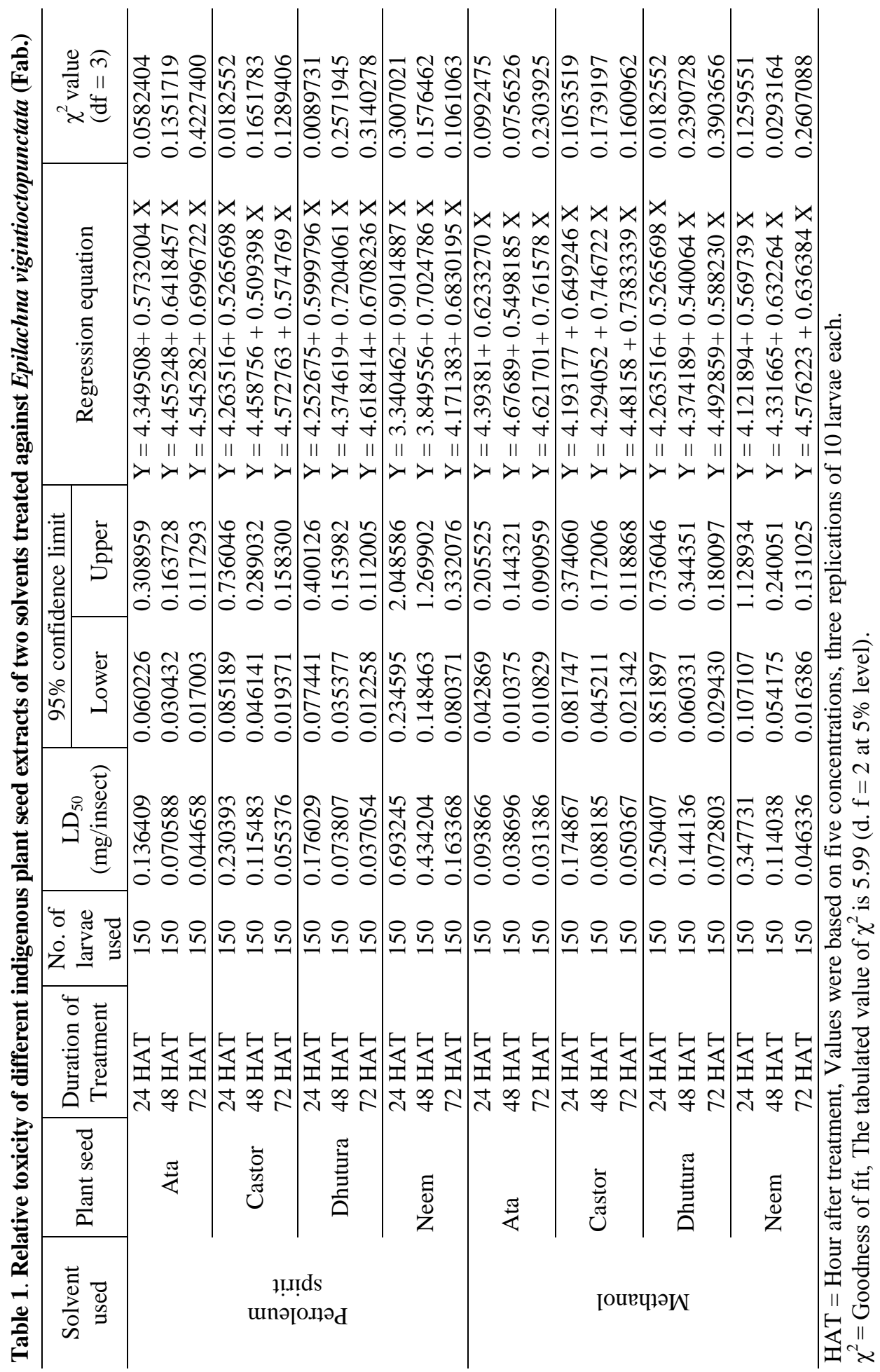




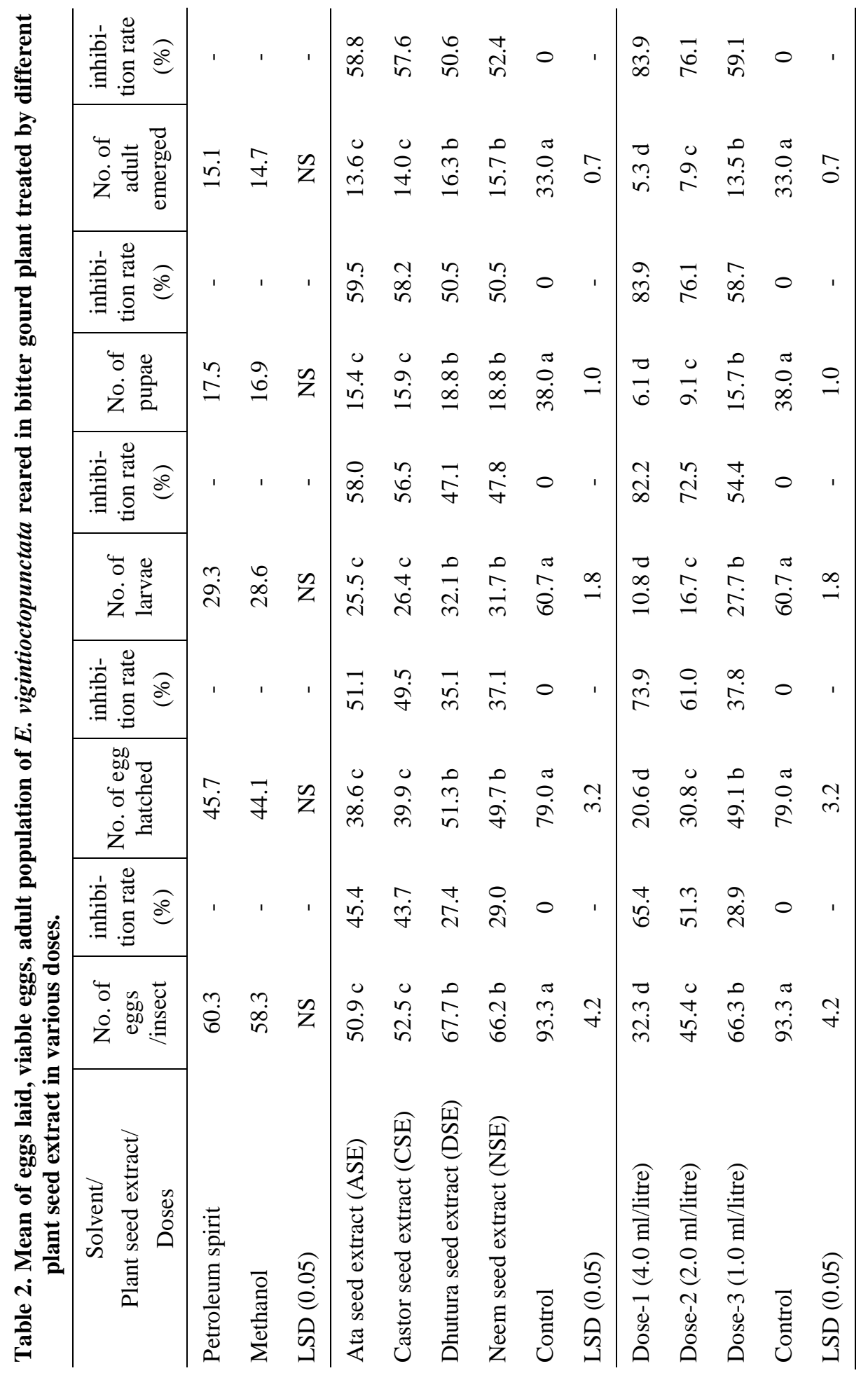


The individual effects of plant extracts on the fecundity, fertility and $F_{1}$ progeny production of $E$. vigintioctopunctata were significantly different among the plant extracts. Among the extracts, ata seed extracts showed maximum efficacy to produce the lowest number of eggs (50.9), viable eggs (38.6) and population production (13.6) followed by castor seed extract. On the other hand, dhutura seed extracts showed the highest number of eggs (67.7), viable eggs (51.3) and population production (16.3). The inhibition rate of the plant extracts ranged from 27.4 to $45.4 \%$ for the number of eggs per insect and 35.1 to $51.1 \%$ for the number of egg hatched. The per cent larval and pupal inhibition was found 47.1 to 58.0 and 50.5 to 59.5 in all tested plant extract while no larval and pupal inhibition was found in control treatment. Similarly, adult emergence inhibition was found 50.6 to $58.8 \%$ among the all the tested plant extracts whereas no per cent inhibition of adult emergence was observed in control treatment. On the basis of fecundity, hatchability, and adult population of $F_{1}$ progeny the order of toxicity was found as ata $>$ castor $>$ neem $>$ dhutura.

The lowest average numbers of eggs laid, eggs hatched and population production were observed in the highest dose of all plant extracts $(4.0 \mathrm{ml} / \mathrm{l})$ and the highest numbers of eggs laid, eggs hatched and population production were found in control (Table 2). The present result indicates that the fecundity, fertility and population production decreased with the increased doses. Statistical analysis showed that all the doses of the plant extracts differed significantly over control and also among the plant extracts (Table 2). The per cent of the highest egg laying inhibition rate was observed in highest dose $(4.0 \mathrm{ml} / \mathrm{l})$ and lowest was in lowest dose $(1.0 \mathrm{ml} / \mathrm{l})$, whereas no egg laying inhibition rate was observed in the control treatment. Similar results were found in per cent inhibition of egg hatch, larval population, pupal population and adult emergence. (Table 2).

The ata seed extract showed the highest efficacy in producing the lowest number of eggs per insect, viable eggs and $F_{1}$ progeny productions in the highest dose $(4.0 \mathrm{ml} / \mathrm{l})$. Similarly, ata showed the highest inhibition (\%) rate in egg hatch, larval population, pupal population and adult emergence (Table 2).

Reddy et al., (1990) reported that petroleum spirit (1\%) extracts of $A$. indica and A. squamosa reduced the number of $H$. vigintioctopunctata larvae infesting brinjal by 88.0 and $92.99 \% ; 85.98$ and $91.02 \%$ at 24 and 72 hours after spraying, respectively. Similarly, Rao et al., (1990) observed that extracts of A. squamosa, Argemone mexicana, Calotropis gigantea, D. stramonium, Eucalyptus globulus, Pongamia glabra and $R$. communis $(0.5 \%)$ produced cent per cent protection against second instar larvae of $H$. vigintioctopunctata. Mondal and Ghatak (2009) found that seed extract of A. squamosa in methanol solvent achieved the highest extent of $76.37 \%$ population reduction at $3 \mathrm{ml} / 1$ of water followed by $64 \%$ in Neem Azal at $5 \mathrm{ml} / 1$ of water and $57 \%$ in petroleum spirit extracts of rhizome of Acorus calamus at $2 \mathrm{ml} / \mathrm{l}$ of water against $H$. vigintioctopunctata. The overall 
result of the present study achieved the bioefficacy of all the tested plant seed extracts against $E$. vigintioctopunctata but among these, ata seed extract showed the highest effect in reducing fecundity, hatchability and adult emergence of the pest.
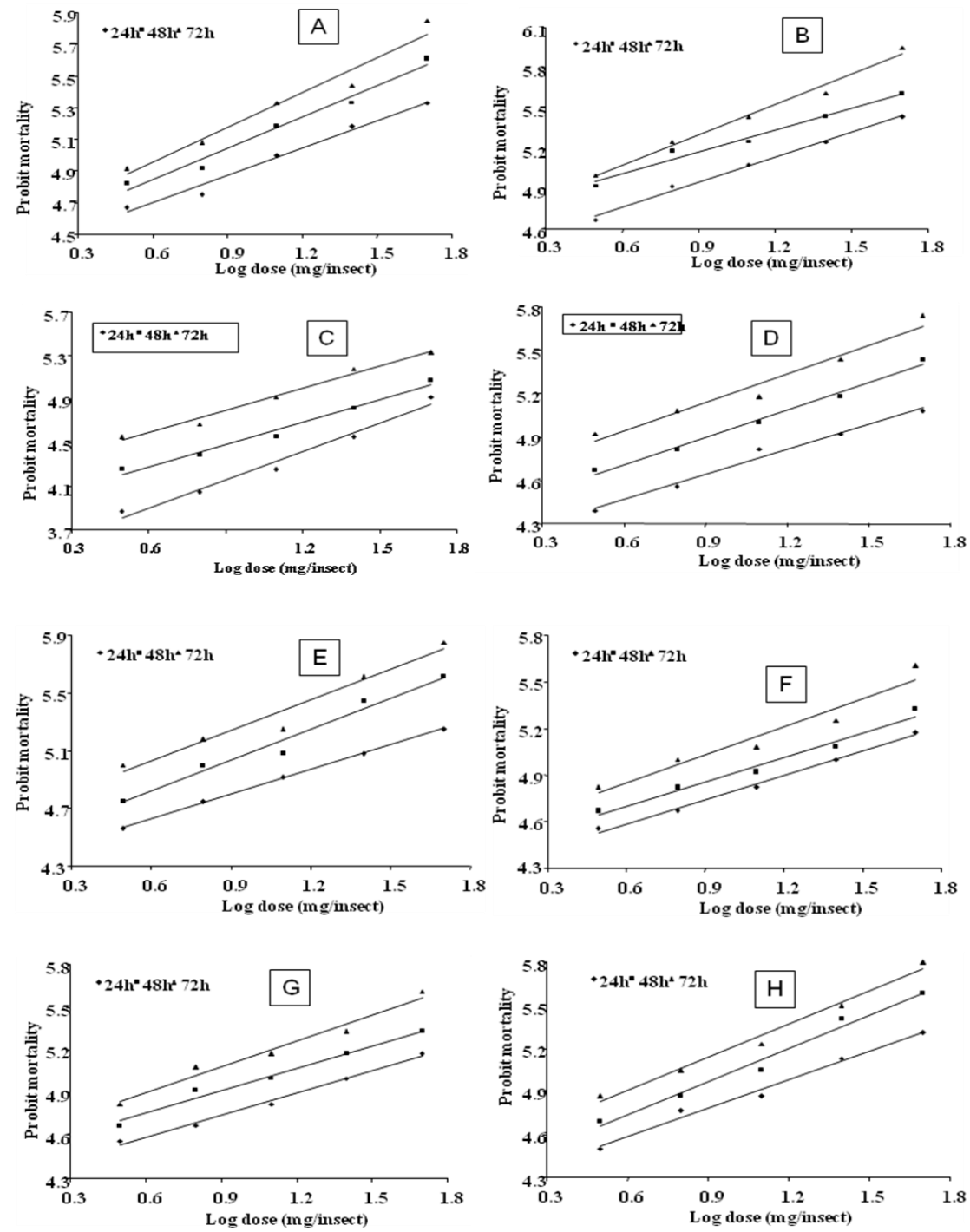

Fig. 1. Relation between log doses and probit mortality for different plant extracts against larvae of $E$. vigintioctopunctata $[\mathrm{A}=$ Petroleun spirit of ata, $\mathrm{B}=$ methanol extract of ata, $\mathrm{C}=$ Petroleun spirit of neem, $\mathrm{D}=$ methanol extract of neem, $\mathrm{E}=$ Petroleun spirit of dhutura, $\mathrm{F}=$ methanol extract of dhutura, $\mathrm{G}=$ Petroleun spirit of castor $\mathrm{H}=$ methanol extract of castor]. 
Babu et al., (1998) reported that the seeds of A. squamosa were found to have insecticidal properties. The larval mortality is probably due to the presence of bioactive chemical components in plant products. The biological activity of ata seed extracts might be attributed to its several alkaloids contents, such as Anonaine, Squamocins B to N, Annotemoyin-1, Annotemoyin-2, Squamocin, Cholesterol and Glucopyranoside etc. (Pandey and Brave, 2011) which might cause mortality to insects.

\section{Conclusion}

The present result indicates the larvicidal efficacy of methanol and petroleum spirit seed extracts of ata, neem, dhutura and castor against $E$. vigintioctopunctata with some promising information on the direct toxicity on the larval mortality and residual toxicity against the fecundity, fertility and $\mathrm{F}_{1}$ progeny production. The mortality increased with increasing doses and exposure time. The dhutura seed extract in petroleum spirit showed the highest toxicity in larval stages whereas in methanol solvent, ata and castor seed extract achieved the highest toxicity at 72 hours exposure time. The results revealed that among the extracts, ata seed extract at maximum dose $(4.0 \mathrm{ml} / 1$ water $)$ showed the highest efficacy with the inhibition of total eggs laid, viable eggs and the number of emergence of $F_{1}$ adult progeny. All the treated doses effectively reduced the epilachna beetle as compared to untreated control.

\section{Acknowledgment}

This investigation is supported by financial grant received from the University Grants Commission (UGC), Bangladesh which is gratefully acknowledged.

\section{References}

Abbott, W. S. 1987. A method of computing the effectiveness of an insecticide. J. American Mosquito control Assoc. 3: 302-303.

Ahmed, K. N. 2007. Effect of biopesticides in the suppression of major insect pests and yield of oilseed crops under different climatic conditions in Bangladesh. Proc. Natl. Symp. Plant Protection-Technology Interface, Assoc. Adv. Plant Protection, Bidhan Chandra Agricultural University, West Bengal, India, December 28-29, Pp. 81-82.

Ahmed, K. N., S. H. A. Pramanik, M. Khatun, A. Nargis and M. R. Hasan. 2010. Efficacy of plant extracts in the suppression of insect pests and their effect on the yield of sunflower crop under different climatic conditions. J. Plant Prot. Sci. 2(1): 53-58.

Ahmed, U. A. M., S. Zuhua, N. H. H. Bashier, K. Muafi, H. Zhongping and G. Yuling. 2006. Evaluation of insecticidal potentialities of aqueous extracts from Calotropis procera Ait. against Henosepilachna elaterii Rossi. J. Applied Sci. 6: 2466-2470. 
Anam, M., M. Ahmad and M. A. Haque. 2006. Efficacy of neem oil on the biology and food consumption of epilachna beetle, Epilachna dodecastigma (Weid.). J. Agric. Rural Dev. 4(1\&2): 83-88.

Babu, P. B. S., J. M. Rao and B. Joy. 1998. Effect of crude oils of Annona squamosa and A. reticulata on feeding and development of Spodoptera litura (Fab.) larvae. J. Insect Sci. 11: 184-185.

Ghatak, S.S. and S. Mondal. 2008. Feasibility of using plant products and biopesticides against epilachna beetle, Henosepilachna vigintioctopunctata (Fab.), infecting brinjal. Indian J. Entomol. 70(3): 278-279.

Islam, K., M. S. Islam and Z. Ferdousi. 2011. Control of Epilachna vigintioctopuntata Fab. (Coleoptera: Coccinellidae) using some indigenous plant extracts. J. Life Earth Sci. 6: 75-80.

Karunaratne, M. M. S. C. and A. P. K. M. C. P. Arukwatta. 2009. Efficacy of three plant species on the mortality and food consumption of Epilachna vigintioctopunctata. Vidyodaya J. Sci. 14: 167-176.

Khan, M. H., B. N. Islam, A. K. M. M. Rahman and M. L. Rahman. 2000. Life table and the rate of food consumption of epilachna beetle, Epilachna dodecastigma (Wied.) on different host plant species in laboratory condition. Bangladesh J. Ent. 10(1-2): 63-70.

Mondal, S. and S. S. Ghatak. 2009. Bioefficacy of some indigenous plant extracts against epilachna beetle (Henosepilachna vigintioctopunctata Fabr.) infesting cucumber. J. Plant Protect. Sci. 1(1):71-75.

National Research Council. 2000. The future role of pesticides in US Agriculture. National Academic Press. Washington, DC. P. 323.

Pandey, N. and D. Brave. 2011. Phytochemical and pharmacological review on Annona squamosa Linn. Int. J. Res. Phar. Bio. Sci. 2(4): 1404 - 1412.

Rahaman, M. A., M. D. H. Prodhan and A. K. M. Maula. 2008. Effect of botanical and synthetic pesticides in controlling Epilachna beetle and the yield of bitter gourd. Int. J. Sustain. Crop Prod. 3(5): 23-26.

Rajagopal, D. and T. P. Trivedi. 1989. Status, bioecology and management of epilachna beetle, Epilachna vigintioctopunctata (Fab.) (Coleoptera: Coccinellidae) on potato in India. Int. J.Pest Manage. 35(4): 410 - 413.

Rao, S. M., K. C. Chitra, D. Gunesekhar and P. K. Rao. 1990. Antifeedent properties of certain plant extracts against second stage larva of Henosepilachna vigintioctopunctata Fabricus. Indian J. Entomol. 52(4): 681-685.

Reddy, P. V. R., K. C. Chitra and P. K. Rao. 1990. Field evaluation of certain plant extracts for the control of brinjal spotted leaf beetle, Henosepilachna vigintioctopunctata. J. Insect Sci. 3: 194-195.

Rohani, A., W. L. Chu, L. Saadiyah, H. L. Lee and S. M. Phang. 2001. Insecticide resistance status of Aedes albopietus and Aedes aegypti collected from urban and rural in major towns of Malaysia. Trop. Biomed. 18(1): 29-39. 
Sreedevi, K., K. C. Chitra and K. Rao. 1993. Effect of certain plant extracts against brinjal leaf beetle, Henosepilachna vigintioctopunctata Fab. under greenhouse conditions. Indian J. Entomol. 55(3): 329-331.

Srivastava, K. P. and D. Butani. 1998. Pest management in vegetable. Research Periodical and Book Publishing House, Pp. 197-225.

Swaminathan, R., M. Sumon and T. Hussain. 2010. Antifeedent activity of some biopesticides on Henosepilachna vigintioctopunctata (Fab.) (Coleoptera: Coccinellidae). J. Biopest. 3 (1 special issue): 77-88.

Zahir, A. A., A. A. Rahuman, C. Kamara, A. Bagavan, G. Elango, A. Sanganan and B. Kumar. 2009. Laboratory determination of efficacy of indigenous plant extracts for parasites control. Parasitol. Res. 105: 453-461. 